\title{
Common symptoms in middle aged women: their relation to employment status, psychosocial work conditions and social support in a Swedish setting
}

\author{
Gunilla Krantz, Per-Olof Östergren
}

\begin{abstract}
Study objective-Over the past few decades there has been a growing interest among researchers, in women's overall life circumstances and their relation to women's health status. For example, paid employment has been considered an important part of women's living conditions in Western societies as the number of women entering the labour market has grown constantly over the past decades. When comparing men's and women's health, one of the most consistent findings is a higher rate of symptoms among women. The most commonly reported symptoms in women are depressive symptoms, symptoms of bodily tension and chronic pain from muscles and joints. The aim of this study was to investigate whether socioeconomic factors, employment status, psychosocial work conditions and social network/support are associated with middle aged women's health status in terms of common symptoms.

Design-A mailed questionnaire was used in a cross sectional design assessing socioeconomic factors, employment status, psychosocial work conditions according to the demand/control model, social network/support and an index based on the $\mathbf{1 5}$ most frequent symptoms presented by middle aged women when seeking health care.
\end{abstract}

Setting-A rural community with 13200 inhabitants in the western part of Sweden. Participants-Women were randomly selected from the general population in the study area, 40 to 50 years of age. The response rate was 81.7 per cent.

Main results-Women who were nonemployed had a significantly increased odds of a high level of common symptoms $(O R=2.82 ; 95 \%$ confidence intervals 1.69 , 4.70), as well as women exposed to job strain $(O R=3.27 ; 1.92,5.57)$, independently of the level of social network/ support. Furthermore, exposure to low social support, low social anchorage or low social participation independently showed significantly increased odds of a high level of common symptoms $(\mathrm{OR}=2.75 ; 1.71,4.42 ; \mathrm{OR}=2.91 ; 1.81,4.69$ and $O R=1.69 ; 1.10,2.61$, respectively).

Conclusions-Work related factors, such as non-employment and job strain, and circumstances within the private sphere, such as social network/support, seem equally important for middle aged women's health status. These findings ought to have important policy implications and also to be of major importance in a primary health care setting when meeting women who seek health care because of common symptoms.

(F Epidemiol Community Health 2000;54:192-199)

Over the past few decades there has been a growing interest among researchers, in women's overall life circumstances and their relation to women's health status. For example, paid employment has been considered an important part of women's living conditions in Western societies.

Women's attendance in paid employment has shown a remarkable development since the early 1960 s in Sweden, and today women constitute 48 per cent of the total work force. ${ }^{1}$

Up until the beginning of the 1990s, about 85 per cent of all Swedish men and women aged 20-64 were part of the workforce. ${ }^{1}$

However, since 1991 the unemployment rate has increased in Sweden. In 1997 about 12 per cent of the work force was suffering from unemployment, the rate being marginally higher for men than for women. ${ }^{2}$

Even though women are just as present as men in the labour market, women more often than men occupy inferior positions, with less possibilities to influence work content, career opportunities and salary. ${ }^{3}$ At the same time women still hold the main responsibility for childbearing and rearing, and women also have a caring responsibility towards elderly relatives and friends.

When comparing men's and women's health, one of the most consistent findings is a higher rate of symptoms among women..$^{2-6}$ Riska states that common symptoms in women mirror psychological distress and depression, related to expectations tied to the traditional female role. ${ }^{4}$

Tibblin and colleagues found that the most common symptoms in women were depressive symptoms, symptoms of bodily tension and chronic pain from muscles and joints. ${ }^{6}$

Swedish women have a higher rate of sickness absence and disability pension than men. ${ }^{7}$ Women, aged 25-54, dominate among all the sick-listed. The high level of sick-listed women between 25 and 40 years of age could partly be explained by complications during pregnancy. The reasons for women above 40 years of age to be sick-listed are manifold, with factors related to paid employment and family 
situation as dominating causes. ${ }^{7}$ Since 1986 and onwards women, aged 40-54, dominate among those who have been granted early retirement pension, with the main diagnoses being diseases in muscles and joints. ${ }^{7}$

Malterud discussed women's symptoms in terms of "ill-defined conditions" and pointed at the lack of scientific knowledge and understanding of how to interpret common symptoms reported by women in, for example, a primary health care setting. ${ }^{8}$ She stated that often there is an ambition within the biomedical paradigm to interpret single symptoms, or sets of symptoms, as related to specific organ systems. Malterud concluded that symptoms often could not be given an adequate interpretation as they represent illness experiences rather than biomedically defined disease. ${ }^{8}$ However, an illness experience without any clear organ related manifestations could be an expression of psychological strain because of exposure to external psychosocial stressors.

Cassel, in his research on the social environment and its influence on disease aetiology, published in 1976, explained how psychosocial processes increase susceptibility to disease or illness through stressors that will change the endocrine balance in the body.

Frankenhaeuser further developed this and described the biopsychosocial model, which provides a way to identify stress inducing environmental factors and analysing their influence on health and wellbeing in the individual. ${ }^{10}$ Through measuring levels of stress hormones in the individual, the impact of particular environmental demands representing long term health risks could be identified. The biopsychosocial model also provides a framework for the study of sex differences in stress and coping..$^{10}$ In a study including male and female middle managers and clerical workers from a large corporation in Sweden, Frankenhaeuser and colleagues showed that after work, female middle managers blood pressure remained high and their stress hormone levels actually increased after work compared with what was seen in male middle managers. The female middle managers' inability to unwind after work was found to be a reflection of their heavy total workload, including demands they experienced from duties at home. ${ }^{11}$

Theorell has pointed at differences between men and women in their response to psychosocial stressors and risk of myocardial infarction: women in occupations where a high proportion of workers report subjective symptoms such as fatigue and headache, have a higher myocardial infarction hospitalisation risk than other women, while no such association was observed among men. ${ }^{12}$ Also, women in occupations in which overtime was reported to be common had a greater risk of becoming hospitalised for myocardial infarction than other women. For men the opposite phenomenon was observed: a moderate amount of overtime was associated with "protection" against hospitalisation for myocardial infarction. ${ }^{12}$

These differences between men and women could be seen from the perspective of traditional male and female roles. In the Swedish society women still carry the main responsibility for childcare and domestic work, also in families where both husband and wife are gainfully employed. Of importance to explain the effect of overtime work is also the fact that men in general enjoy more decision latitude and intellectual discretion in their jobs than women do. ${ }^{12}$

The concern guiding the present research was that psychosocial factors and traditional gender roles often cause stress reactions in women, resulting in a high level of common symptoms, which, if not adequately met, could turn into manifest disease.

The aim of this study was to investigate whether socioeconomic factors, employment status, psychosocial work conditions and social network/support are associated with middle aged women's health status in terms of a high level of common symptoms.

\section{Methods}

POPULATION

This study is based on a random sample of 486 women, which equals a random 50 per cent of the general population of women, $40-50$ years of age, living in a rural community of 13200 inhabitants in the western part of Sweden. A questionnaire was sent by mail in September 1993. The response rate was 81.7 per cent, resulting in a study population of 397 women.

The community chosen in this study, Lilla Edet, is a rural community, which mirrors average life circumstances in the country. ${ }^{13}$ Main employment is found within paper industry and health and social services. People also commute to a nearby town to find work within the car manufacturing industry. As for the country, women are mainly employed within the clerical, public service, sales and factory sectors, while men find their employment mainly within business and the industrial sector. The unemployment rate is close to the average in Sweden, at times somewhat higher. At the time of the study, 4.0 per cent of the women and 7.2 per cent of the men, aged 20 to 64 , were seeking paid employment compared with 4.8 and 7.6 per cent respectively, for the country. Average annual number of days of sickness absence was 38 for women and 25 for men, aged 45-64, while the equivalent figures for Sweden were 34 and 27, respectively. ${ }^{13}$

All data in this study were obtained through self reports. The questionnaire contained items on socioeconomic and work related conditions such as age, nationality, cohabitation status, educational level, income level, employment status, present occupation, sickness absence, disability pension, psychosocial work conditions, social network and support and items covering common symptoms.

\section{MEASUREMENTS}

To measure the health status, the Common Symptoms in the General Population of women instrument (CSGP-scale) was used, composed of 15 physical and mental symptoms that, according to other studies, are most prevalent in women. ${ }^{14}$ The presence of each type of symptom was ranked from "almost 
Table 1 The prevalence of the 15 symptoms forming the Common Symptoms in General Practice scale $(C S G P)(n=397)$

\begin{tabular}{lllll}
\hline & $\begin{array}{l}\text { Almost daily } \\
(2 \text { pts } n \text { (\%) }\end{array}$ & $\begin{array}{l}\text { Weekly (1 pt) } \\
n(\%)\end{array}$ & $\begin{array}{l}\text { Monthly/ never } \\
(0 \text { pts } n \text { (\%) }\end{array}$ \\
\hline 1 & Heartburn & $17(4.3)$ & $23(5.8)$ & $357(89.9)$ \\
2 & Stomach pain & $16(4.0)$ & $27(6.8)$ & $354(89.2)$ \\
3 & Palpitation & $11(2.8)$ & $30(7.6)$ & $356(89.7)$ \\
4 & Breathing disorder & $12(3.0)$ & $11(2.8)$ & $374(94.2)$ \\
5 & Listlessness & $15(3.8)$ & $23(5.8)$ & $359(90.4)$ \\
6 & Irritability & $28(7.1)$ & $85(21.4)$ & $284(71.5)$ \\
7 & Restlessness & $20(5.0)$ & $34(8.6)$ & $343(86.4)$ \\
8 & Nervousness/anxiety & $27(6.8)$ & $47(11.8)$ & $323(81.4)$ \\
9 & Depression & $16(4.0)$ & $25(6.3)$ & $356(89.7)$ \\
10 & Headache & $25(6.3)$ & $58(14.6)$ & $314(79.1)$ \\
11 & Tiredness & $81(20.4)$ & $114(28.7)$ & $202(50.9)$ \\
12 & Muscular tension & $74(18.6)$ & $55(13.9)$ & $268(67.5)$ \\
13 & Chest pain & $12(3.0)$ & $17(4.3)$ & $368(92.7)$ \\
14 & Low back pain & $59(14.9)$ & $28(7.1)$ & $310(78.1)$ \\
15 & Pain in the joints & $92(23.2)$ & $48(12.1)$ & $257(64.7)$ \\
& (for example, shoulder, knee) & & & \\
\hline
\end{tabular}

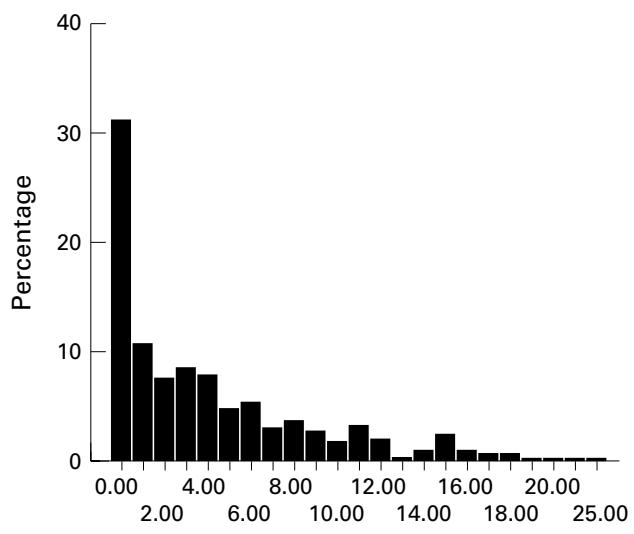

Figure 1 The distribution of score of the CSGP-index in the sample, presented as percentages. Range of CSGP-index: $0-30(n=397)$.

every day" (two points), to "every week" (one point) and to "every month"/ "almost never or never", which were both given zero points to narrow the definition of cases and avoid a mixture of cases and non-cases (table 1).

The distribution of CSGP points in the sample is displayed in figure 1. The variable was dichotomised by the lower tertile of the distribution so that five or more points on the scale defined a "high" level of symptoms (34 per cent of the study population).

Age was classified into two groups; 40-44 and 45-50 years of age. Nationality was dichotomised into born in Sweden or born abroad. Cohabitation status was classified into two groups; cohabiting with someone or not. Educational level was based on the women's number of years of education and divided into four groups; completed primary education (nine years of schooling), primary education plus vocational training (10-11 years), secondary education (12 years) and tertiary (university) studies ( $>12$ years). Educational level was further dichotomised into completed primary education versus longer schooling when used in the multivariate analyses.

Occupational class was classified by means of the manual used by Statistics Sweden into two groups: manual workers and non-manual employees. ${ }^{15}$ For those not currently employed, their latest job title was used for classification. All but 49 (12.3 per cent) respondents were classified, of these 13 (3.3 per cent) were students, eight (2.0 per cent) were housewives and 28 ( 7.1 per cent) could not be classified because of insufficient self reported data.

The income of the respondents (the woman's salary before taxation) was classified into three groups; less than 10000 Swedish crowns (SEK) per month, 10 000-15000 SEK per month and more than 15000 SEK per month. Income was dichotomised at the level of 10000 SEK per month when used in multivariate analyses.

Employment status was classified into two groups, being employed or non-employed. Of the employed women, 55 per cent were in a full time job while 40 per cent were in part-time employment (working more than half time but less than 35 hours a week) and five per cent were in a half time position or less. In the statistical analyses all those who were in paid employment were combined, as the health consequences of part-time employment seems more similar to full time employment than to non-employment. ${ }^{16}$

The non-employed group included women seeking paid employment (unemployed), women who were on long term sickness absence or disability pension, and as well students and housewives. Long term sickness absence was defined as six months or more.

A Swedish version of Karasek's demandcontrol instrument was used to classify psychosocial work conditions and job strain. ${ }^{17}$ In this study, a psychological demand score above the median and a decision latitude score below the median defined job strain.

To measure social network and support a model developed by Hanson and Östergren was used. ${ }^{18}$ It estimates degree of social support, social anchorage and social participation. Social network refers to the structural aspects of a person's social relationships and is operationalised into two indices assessing two different dimensions, social anchorage and social participation. Social anchorage describes to what degree a person belongs to formal and informal groups and also the feeling of membership in these groups. Social participation describes how actively a person takes part in activities of formal and informal groups in society. Social support refers to the functional aspects of a person's interactions with his/her social network. A detailed assessment of the test-retest stability and different aspects of validity of this instrument has been published elsewhere. ${ }^{19}$ Each of the three indices was dichotomised at the lower tertile, where the women who scored below were considered exposed to poor social support, low social anchorage and low social participation, respectively.

\section{STATISTICAL METHODS}

Odds ratios were used to estimate the bivariate association between socioeconomic (age, nationality, cohabitation status, educational level, occupational class, income) and work related variables (employment status, job strain) and also social network and support-and a high level of common symptoms.

Multiple logistic regression analyses were used to adjust for age and for testing of 
Table 2 Comparison between respondents and non-respondents concerning work related background variables

\begin{tabular}{|c|c|c|c|c|}
\hline & \multicolumn{2}{|c|}{$\begin{array}{l}\text { Respondents } \\
\text { (397) }\end{array}$} & \multicolumn{2}{|c|}{$\begin{array}{l}\text { Non-respondents } \\
\text { (89) }\end{array}$} \\
\hline & $n$ & $\%$ & $n$ & $\%$ \\
\hline In paid employment & 320 & 80.6 & 56 & 62.9 \\
\hline Non-employed & 36 & 9.1 & 14 & 15.7 \\
\hline Sickness absence & 8 & 2.0 & 7 & 7.9 \\
\hline Early retirement pension & 20 & 5.0 & 12 & 13.5 \\
\hline Mean age (SD) & & $45 \quad(3.8)$ & & $45 \quad(2.9)$ \\
\hline
\end{tabular}

different tentative models of the association between the dependent and independent variables. Nationality and cohabitation status were both excluded in the multivariate analyses as they were only weakly associated with a high level of common symptoms and with the other independent variables. So was income but this variable was included so that our results could be compared with other studies.

In the multivariate analyses, firstly age and employment status were entered (model 1), then educational level in addition (model 2) then income in addition (model 3), followed by social support, social anchorage and social participation (model $4 \mathrm{a}-\mathrm{c}$ ). The three last vari-

Table 3 Associations between sociodemographic and work related factors and risk of a high level of common symptoms in middle aged women, presented as crude odds ratios $(O R)$ and $95 \%$ confidence intervals (95\% CI)

\begin{tabular}{|c|c|c|}
\hline Sociodemographic and work related variables & $\begin{array}{l}\text { High level of } \\
\text { symptoms (\%) }\end{array}$ & Crude OR $(95 \%$ CI) \\
\hline \multicolumn{3}{|l|}{ Age (y) } \\
\hline $40-44(n=170)$ & 31.8 & 1 (reference) \\
\hline $45-50(n=209)$ & 36.4 & $1.23(0.80,1.88)$ \\
\hline \multicolumn{3}{|l|}{ Nationality } \\
\hline Born in Sweden $(n=331)$ & 33.2 & 1 (reference) \\
\hline Born in other country $(n=66)$ & 37.9 & $1.23(0.68,2.20)$ \\
\hline \multicolumn{3}{|l|}{ Cohabitation status } \\
\hline Cohabiting $(n=337)$ & 33.0 & 1 (reference) \\
\hline Not cohabiting $(n=57)$ & 42.1 & $1.48(0.80,2.74)$ \\
\hline \multicolumn{3}{|l|}{ Educational level } \\
\hline Tertiary education $(n=85)$ & 24.7 & 1 (reference) \\
\hline Secondary education $(n=64)$ & 37.5 & $1.83(0.90,3.71)$ \\
\hline Primary education plus vocational training $(n=98)$ & 33.7 & $1.55(0.81,2.95)$ \\
\hline Primary education $(n=133)$ & 40.5 & $2.08(1.14,3.80)$ \\
\hline \multicolumn{3}{|l|}{ Occupational class } \\
\hline Non-manual $(n=170)$ & 28.2 & 1 (reference) \\
\hline Manual $(n=178)$ & 36.0 & $1.43(0.91,2.24)$ \\
\hline \multicolumn{3}{|l|}{ Income } \\
\hline >15000 SEK/month $(\mathrm{n}=55)$ & 29.1 & 1 (reference) \\
\hline 10-15000 SEK/month $(\mathrm{n}=151)$ & 34.4 & $1.28(0.65,2.51)$ \\
\hline$<10000$ SEK/month $(\mathrm{n}=167)$ & 36.5 & $1.40(0.72,2.72)$ \\
\hline \multicolumn{3}{|l|}{ Employment status } \\
\hline Employed $(n=320)$ & 29.3 & 1 (reference) \\
\hline Non-employed (all) $(\mathrm{n}=77)$ & 53.9 & $2.82(1.69,4.70)$ \\
\hline \multicolumn{3}{|l|}{ Of the non-employed: } \\
\hline students/home-makers/unemployed (n=49) & 43.8 & $1.87(1.01,3.47)$ \\
\hline sick-leave/disability pension $(n=28)$ & 71.4 & $6.01(2.56,14.13)$ \\
\hline \multicolumn{3}{|l|}{ Social network/support indices } \\
\hline \multicolumn{3}{|l|}{ Social support: } \\
\hline High/medium $(n=303)$ & 28.4 & 1 (reference) \\
\hline Low $(n=94)$ & 52.1 & $2.75(1.71,4.42)$ \\
\hline \multicolumn{3}{|l|}{ Social anchorage: } \\
\hline High/medium $(n=303)$ & 28.1 & 1 (reference) \\
\hline Low $(n=94)$ & 53.2 & $2.91(1.81,4.69)$ \\
\hline \multicolumn{3}{|l|}{ Social participation: } \\
\hline High/medium $(n=261)$ & 29.9 & 1 (reference) \\
\hline Low $(n=136)$ & 41.9 & $1.69(1.10,2.61)$ \\
\hline \multirow{2}{*}{\multicolumn{3}{|c|}{$\begin{array}{l}\text { Work related psychosocial factors (only those employed are included, } n=320 \text { ) } \\
\text { Psychological job demands: }\end{array}$}} \\
\hline & & \\
\hline Low $(n=219)$ & 24.7 & 1 (reference) \\
\hline & 44.9 & $2.49(1.45,4.28)$ \\
\hline \multicolumn{3}{|l|}{ fob decision latitude: } \\
\hline $\operatorname{High}(n=217)$ & 25.3 & 1 (reference) \\
\hline Low $(n=91)$ & 38.5 & $1.84(1.09,3.10)$ \\
\hline \multicolumn{3}{|l|}{ Fob strain: } \\
\hline No job strain $(n=206)$ & 21.8 & 1 (reference) \\
\hline Job strain $(n=88)$ & 47.7 & $3.27(1.92,5.57)$ \\
\hline
\end{tabular}

KEY POINTS

- There is a lack of empirical knowledge on the background of common symptoms among women.

- In this study, non-employment was significantly associated with a high level of common symptoms in middle aged Swedish women.

- Among the employed women job strain was significantly associated with a high level of common symptoms.

- Social network/support was, independently of employment status and job strain, significantly associated with a high level of common symptoms.

- The health effects of non-employment/ job strain and social network/support in middle aged women warrant a policy response.

ables were analysed separately in three different models as they were relatively highly correlated.

Educational level and occupational class seemed inappropriate to include in the same model as they were highly correlated $(r=0.52)$. In this situation educational level was chosen because this variable has been shown to predict health of non-employed women better than occupational class. ${ }^{20}$

The same type of analyses were then repeated, including only those women who were in paid employment, where the variable employment status was exchanged by the variable job strain, to explore the contribution of work conditions to a high level of common symptoms.

For all statistical purposes the SPSS-package was used. ${ }^{21}$ Statistical significance was determined at the 95 per cent confidence interval level.

The Ethics Committee of Gothenburg University has approved of the study.

\section{Results}

When analysing work related background variables among the non-respondents in comparison with the respondents, the following was found: of the respondents 320 (80.6 per cent) were employed compared with 56 (63 per cent) of the non-respondents. At the same time, the non-respondents were to a higher degree sicklisted or in early retirement pension schemes (table 2).

The bivariate analyses (table 3 ) showed that the following variables were significantly related to a high level of common symptoms: completed primary education with an odds ratio of 2.08 (1.14, 3.80), non-employment $(\mathrm{OR}=2.82 ; 1.69,4.70)$ and job strain $(\mathrm{OR}=3.27$; 1.92, 5.57). Furthermore, poor social support $(\mathrm{OR}=2.75 ; 1.71,4.42)$, low social anchorage $(\mathrm{OR}=2.91 ; 1.81,4.69)$ and low social participation $(\mathrm{OR}=1.69 ; 1.10,2.61)$ were also significantly associated with a high level of common symptoms.

When further examining the non-employed it was found that being on long term sickness 
Table 4 Association between employment status and risk of a high level of common symptoms in middle aged women, presented as adjusted OR and confidence intervals $(95 \%$ CI) $(n=397)$

\begin{tabular}{|c|c|c|c|c|c|c|}
\hline Variable & Model 1 & Model 2 & Model 3 & Model $4 a$ & Model $4 b$ & Model $4 c$ \\
\hline Employment status (non-active versus active) & $2.63(1.56,4.41)$ & $2.51(1.48,4.23)$ & $3.84(2.08,7.11)$ & $3.62(1.93,6.79)$ & $3.80(2.02,7.14)$ & $3.67(1.97,6.84)$ \\
\hline Educational level (low versus high) & & $1.46(0.92,2.30)$ & $1.60(0.99,2.58)$ & $1.53(0.94,2.50)$ & $1.68(1.03,2.74)$ & $1.36(0.82,2.25)$ \\
\hline Income (low versus high) & & & $0.73(0.45,1.20)$ & $0.72(0.44,1.18)$ & $0.73(0.44,1.19)$ & $0.70(0.43,1.15)$ \\
\hline Social support (low versus high) & & & & $2.75(1.61,4.67)$ & & \\
\hline Social anchorage (low versus high) & & & & & $2.77(1.64,4.68)$ & \\
\hline Social participation (low versus high) & & & & & & $1.82(1.10,3.00)$ \\
\hline
\end{tabular}

Table 5 Association between exposure to psychosocial work conditions (job strain) and risk of a high level of common symptoms in employed middle aged women, presented as adjusted $O R$ and confidence intervals (95\% CI) $(n=320)$

\begin{tabular}{|c|c|c|c|c|c|c|}
\hline Variable & Model 1 & Model 2 & Model 3 & Model $4 a$ & Model $4 b$ & Model $4 c$ \\
\hline Job strain (presence versus absence) & $3.44(1.98,5.99)$ & $3.63(2.07,6.36)$ & $3.66(2.09,6.44)$ & $3.25(1.82,5.81)$ & $3.37(1.90,5.97)$ & $3.69(2.09,6.52)$ \\
\hline Income (low versus high) & & $0.85(0.48,1.50)$ & $0.81(0.46,1.43)$ & $0.79(0.44,1.43)$ & $0.81(0.45,1.44)$ & $0.78(0.44,1.39)$ \\
\hline Educational level (low versus high) & & & $1.36(0.75,2.45)$ & $1.24(0.68,2.28)$ & $1.40(0.78,2.54)$ & $1.16(0.62,2.15)$ \\
\hline Social support (low versus high) & & & & $3.25(1.69,6.27)$ & & \\
\hline Social anchorage (low versus high) & & & & & $2.02(1.08,3.79)$ & \\
\hline Social participation (low versus high) & & & & & & $1.72(0.92,3.19)$ \\
\hline
\end{tabular}

absence, including disability pension, was significantly associated with a high level of common symptoms (OR=6.01; 2.56, 14.13). Non-employment for other reasons (being a student, homemaker or unemployed) was as well significantly associated with a high level of common symptoms, $\mathrm{OR}=1.87(1.01,3.47)$.

The results of the multivariate analyses (table 4) showed that non-employment remained a statistically significant independent risk factor with a slight further increase of the odds ratio $(\mathrm{OR}=3.84 ; 2.08,7.11)$ when educational level and income were entered into the model (model 2-3). When social support, social anchorage or social participation was entered into the analysis (model $4 \mathrm{a}-\mathrm{c}$ ), the odds ratios for a high level of common symptoms among non-employed women remained of the same magnitude. Furthermore, the odds ratios for a high level of common symptoms regarding women exposed to a low level of social support, social anchorage or social participation remained statistically significant and of about the same strength as in the bivariate analyses also when the employment status and job strain variables were entered $(\mathrm{OR}=2.75 ; 1.61,4.67: \mathrm{OR}=2.77 ; 1.64$, 4.68 and $\mathrm{OR}=1.82 ; 1.10,3.00$, respectively).

A similar pattern was observed when substituting the employment status variable with the job strain variable in employed women (table 5). That is, the association between job strain and a high level of common symptoms remained statistically significant and of the same level $(\mathrm{OR}=3.66 ; 2.09,6.44)$ when income and educational level were entered into the analysis (model 2-3). Entering social support, social anchorage or social participation (three separate models, $4 \mathrm{a}-\mathrm{c}$ ) did only marginally alter the risk of a high level of common symptoms among those exposed to job strain.

Furthermore, the risk of a high level of common symptoms in employed women with poor social support, low social anchorage or low social participation remained of the same magnitude as in the bivariate analyses also when the employment status and job strain variables were entered $(\mathrm{OR}=3.25 ; 1.69,6.27, \mathrm{OR}=2.02$; $1.08,3.79, \mathrm{OR}=1.72 ; 0.92,3.19$, respectively).

\section{Discussion}

The aim of this study was to examine how socioeconomic factors, employment status, psychosocial work conditions and social network/support were associated with health status in a sample of Swedish middle aged women.

We found that non-employed women and women exposed to job strain had a significantly increased odds for a high level of common symptoms, independently of the level of social network and support. We also noticed that exposure to low levels of social support, social anchorage or social participation displayed increased odds for a high level of common symptoms, independently of employment status and psychosocial work conditions.

The findings in this study could be biased by selection, misclassification and confounding.

There were more non-employed women among the non-respondents than among the respondents in this study. Our results imply that ill health was comparatively more prevalent among non-employed women. If this is paired with a general tendency that ill health is associated with a hesitation to participate in studies of this kind, ${ }^{22}$ this could infer selection bias-that is, there would be a larger proportion of unemployed women with a high level of symptoms among non-participants compared with participants. Therefore, the inclusion of the non-participants might have increased the association between nonemployment and a high level of common symptoms. However, as the non-participants in this study only constituted 18.3 per cent of the cohort, this potential selection bias would not affect the findings to any considerable degree.

Concerning selection bias in terms of geographical criteria - the basis for defining the study population - we know that the population in the selected community is rather stable in terms of moving in or out of the area. Therefore, it seems unlikely that selection by means of differential geographical mobility would seriously bias the findings. ${ }^{13}$

The instrument used to assess psychosocial work conditions, for example, Karasek's demand-control model, is a well recognised instrument of good validity and reliability, and 
it is judged to be a rather stable predictor of the person's health status. ${ }^{17}{ }^{23}$ Similarities are obtained when comparing levels of job strain between occupations in different populations in various countries, which suggests a high degree of robustness. ${ }^{23}$ The instrument used to assess social network and support has also been used in a number of previous studies and has documented good validity and reliability. ${ }^{19}$

Both instruments were initially developed and tested on men and there was an a priori risk that they could not be used on women. However, both instruments have been used in other studies and have documented good validity and reliability also when applied on women. ${ }^{12} 19$

The CSGP-instrument is based on a cluster of symptoms often experienced by women. ${ }^{14}$ The selected symptoms also correspond to what has been described in Norwegian studies as being common symptoms among women seeking care in general practice. ${ }^{24}{ }^{25}$ Internal consistency and external comparison with Symptom Check List $90^{26}$ showed that the CSGP-index was a coherent instrument. ${ }^{14}$

Furthermore, our results could have been affected by the fact that common symptoms, job strain and social network and support were all based on self reports. If the reporting in the three instruments had been affected by some third factor- such as a general negativistic attitude, which would in turn make the women rate their overall living conditions as generally bad-this would lead to an overestimation of the contributions of job strain and social network and support. However, the fact that several of the independent variables showed low intercorrelation, and came out as independent of each other in the multivariate analysis, speaks strongly against such an assumption. Furthermore, measures of self rated health used in other studies seem to guarantee an acceptable validity in that they predict future health surprisingly accurately. ${ }^{27}$

There are two possible ways of interpreting the multivariate analyses in this study. They could on the one hand, be viewed as traditional confounding analyses. In such case there is little evidence of confounding as the odds ratios for a high level of common symptoms regarding non-employed women, or women in a job strain situation, remained of the same strength in all models in the regression analysis. On the other hand, the analyses could be viewed as a test of tentative causal chains of factors that contribute to a high level of common symptoms in middle aged women. Employment status and job strain could for instance be plausible parts of the same chain of events as social network and support. However, our findings did not support this either, as the odds for a high level of common symptoms remained of the same strength when social network and support were entered into the analysis.

Thus, we found that employment status/job strain and social network/support indices did not confound, alternatively seemed not to be parts of the same causal chain. Rather, these factors seemed to be independent risk factors, each associated with a high level of common symptoms in middle aged women.

This study is cross sectional and therefore on the whole, the interpretation of the causal direction regarding some of the exposures and outcomes should be made with great caution. However, the causal direction of age and nationality could hardly be but one, but regarding the association between educational level or socioeconomic status and a high level of common symptoms, the dominant causal direction might be less obvious. From a commonsense perspective it seems more probable though, that educational level/ socioeconomic status causes common symptoms in middle aged women, rather than vice versa. The same applies to income ${ }^{28}$ and cohabitation status. If the outcome had been serious or disabling conditions, in contrast with a high level of common symptoms, the situation might have been different.

However, the presence of a high level of common symptoms might exert influence on the ability to enter and stay in the work force, from which follows that there might be an increased risk of non-employment among women suffering a high level of common symptoms. Ross and Mirowsky investigated the cross sectional correlation between employment and health with the aim of finding out which one is the most important pathway, the social causation or the social selection mechanism. ${ }^{29}$ They found that causation and selection were mutually reinforcing, not mutually exclusive, in that full time employment improves health, and health improves the odds of full time employment.

As job strain is strongly determined through the person's occupation/educational level it seems probable that job strain would cause a high level of common symptoms. Furthermore, Theorell and Karasek have shown that job strain is able to cause stress and cardiovascular disease in both men and women. ${ }^{30}$

Berkman and Syme investigated the causal direction of social network and support in relation to morbidity and mortality in the Alameda County study. ${ }^{31}$ They found that social circumstances, such as social isolation, have pervasive health consequences and that social factors may influence host resistance and affect vulnerability to disease in general.

From the Netherlands Stronks and coworkers described the strong association between income and health and concluded that, for a large part, it could be interpreted in terms of an inter-relation between employment status, income and health. ${ }^{32}$ After controlling for employment status, they found that income was related to perceived general health, especially among women. They interpreted this as an effect of material factors on health that may be important. We found only a weak and statistically non-significant association between income and a high level of common symptoms. However, in our study, the variable income included only the woman's own salary and no other sources were included such as husband's salary or allowances of any kind, this despite the fact that in many cases a considerable part 
of a family's income consists of transfer payments. Therefore, the lack of a significant association in our study between income and a high level of common symptoms could be because of an inaccuracy as only the women's own salaries were included, which might be a too weak an instrument to investigate the effect of income.

A number of studies confirm that employed women are physically and psychologically healthier than non-employed women, ${ }^{29} 3334$ which corresponds well with our findings. Sorensen and Verbrugge found that the positive effect of paid employment for women is mediated through a higher degree of self esteem and improved opportunities for women to exert influence over their own lives by becoming economically less dependent. ${ }^{35}$

Our conclusion from this study is that non-employment, and factors related to paid employment such as job strain, together with factors within the private sphere, such as a low level of social network/support, independently of each other influence middle aged women's health status in terms of a high level of common symptoms.

These findings could have important policy implications. In Sweden women are in paid employment to about the same degree as men, but women more often occupy subordinate positions at the work place and have fewer possibilities than men to influence work conditions, salary and career opportunities. ${ }^{3}$ Moreover, women occupy high strain jobs more often than men do. According to a national survey undertaken in 1991, 21 per cent of the female workforce were in high strain jobs while the corresponding figure for men was only 12 per cent. ${ }^{36}$ If women's work conditions could be improved, to be similar to men's, there are good reasons to believe that women's overall health status would improve. Areas that need to be improved concern power and decision making authority, and adequate time devoted to the work tasks.

The findings could also be of importance in a primary health care setting when considering the understanding of women seeking health care because of "ill defined conditions". The need for exclusion of specific biomedical reasons for such symptoms among female patients should be balanced against a prominent risk of medicalising gender related psychosocial distress, caused for instance by adverse work conditions or other psychosocial factors.

This kind of symptom is common among the general population of women in Sweden and in other western European countries. It causes a lot of suffering in terms of pain and impaired function. It is of a major public health interest to improve the understanding and find preventive measures to avoid sending women, aged 40 to 50, into long term sickness absence or disability pension, when they could still make significant contributions in the labour market and in society at large.
Funding: this study was supported by grants from the Älvsborg County Council, from the National Institute of Public Health and the Swedish Council for Social Research.

Conflicts of interest: none.

1 Social rapport 1997 (National report on the social situation 1997). Stockholm: Socialstyrelsen (National board of health and welfare), 1997.

2 Folkhälsorapport 1997 (Public health report 1997). Stockholm: Socialstyrelsen (National board of health and welfare), 1997.

3 Hall EM. Double exposure: the combined impact of the home and work environments on psychosomatic strain in Swedish women and men. Int f Health Serv 1992;22:23960.

4 Riska E. Kvinnors sjuklighet-den bortglömda siffran i hälsoforskningen (Women's illnesses - the forgotten figure in forskningen (Women's illnesses - the forgotten figure in
health research). In: Hägglund U, Riska E, eds. Kvinnors health research). In: Hägglund U, Riska E, eds. Kvinnors
hälsa och ohälsa - social kontroll av kvinnor (Women's health hälsa och ohälsa - social kontroll av kvinnor (Women's health and illnesses - the social control of women).

5 Verbrugge LM. Wingard DL. Sex differentials in health and mortality. Women Health 1987;12:103-43.

6 Tibblin G. Bengtsson C, Furunes B et al. Symptoms by age and sex. Scand $\mathcal{f}$ Prim Health Care 1990;8:9-17.

7 Jämställd vård (Equality in care). Huvudbetänkande av Utredningen om bemötande av kvinnor och män inom hälsooch sjukvården. (Report on treatment of women and men within the health care services). Stockholm: Socialdepartementet, Statens offentliga utredningar 1996. SOU 1996: 133.

8 Malterud K. Illness and disease in female patients. I. Pitfalls and inadequacies of primary health care classification and inadequacies of primary health care classification systems - a the th

9 Cassel J. The contribution of the social environment to host resistence. Am f Epidemiol 1976; 104:107-23.

10 Frankenhaeuser $M$. The psychophysiology of sex differences as related to occupational status. In: Frankenhaeuser M, Lundberg U, Chesney M, eds. Women, work and health: stress and opportunities. NewYork: Plenum Press, 1991.

11 Frankenhaeuser M, Lundberg U, Fredrikson M, et al. Stress on and off the job as related to sex and occupational status in white-collar workers. Fournal of Organizational Behavior 1989;10:321-46.

12 Theorell T. On cardiovascular health in women: results from epidemiological and psychosocial studies in Sweden. In: Frankenhaeuser $\mathrm{M}$, Lundberg $\mathrm{U}$, Chesney $\mathrm{M}$, eds. Women, Press, 1991.

13 Statistics Sweden. The equality programme. Örebro: SCBtryck, 1993.

14 Krantz G, Östergren P-O. Women's health: Do symptoms in women mirror general distress or specific disease entities? Scand $\mathcal{F}$ Public Health (in press)

15 Statistics Sweden. Occupations in population and housing census 1985 according to Nordic standard occupational classification and Swedish socio-economic classification. Örebro: SCB-tryck, 1989.

16 Verbrugge LM. Multiple roles and physical health of women and men. F Health Soc Behav 1983;24:16-30.

17 Karasek R, Theorell T. Healthy work, stress productivity and the reconstruction of working life. New York: Basic Books, 1990.

18 Hanson BS, Östergren P-O. Different social network and social support characteristics, nervous problems and insomnia: theoretical and methodological aspects on some insomnia: theoretical and methodological aspects on some Malmö, Sweden. Soc Sci Med 1987;25:849-59.

19 Hanson BS, Östergren P-O, Elmståhl S, et al. Reliability and validity assessments of measures of social networks, social support and control- results from the Malmö shoulder and neck study. Scand F Soc Med 1997;25:249-57.

20 Arber S. Integrating non-employment into research on health inequalities. Int f Health Serv 1996;26:445-81.

21 Norusis M. SPSS for Windows. Professional Statistics release 6.1. Chicago: SPSS Inc, 1994.

22 Janzon L, Hanson BS, Isacsson S-O, et al. Factors influencing participation in health surveys. Results from the prospective population study "Men born in 1914", Malmö, prospective population study "Men born in 1914", Malm

23 Kristensen TS. Arbejdsmiljö, stress og helbred $i$ den danske slagteribranche (Work environment, stress and health among teribranche (Work environment, stress and health among
Danish slaughterhouse workers). [PhD thesis.] Danish slaughterhouse workers). [PhD

24 Brage S, Tellnes G. ICPC i allmenpraksis (ICPC in general practice). Tidskr Nor Laegeforening 1992;112:2656-9.

25 Nylenna $M$. Why do our patients see us? Scand $\dot{f}$ Prim Health Care 1985;3:155-62.

26 Derogatis LR, Cleary PA. Confirmation of the dimensional structure of the SCL-90: a study in construct validation. $\mathcal{F}$ Clin Psychol 1977;33:981-9.

27 Self-rated health-a useful concept in research, prevention and clinical medicine. Stockholm: Forskningsrådsnämnden (The Swedish council for planning and coordination of research), 1996.

28 Stronks K, van de Mheen D, Mackenbach J. A higher prevalence of health problems in low income groups: does it reflect relative deprivation? F Epidemiol Community Health 1998;52:548-57.

29 Ross CE, Mirowsky J. Does employment affect health? $\mathcal{f}$ Health Soc Behav 1995;36:230-43. 
30 Theorell T, Karasek RA. Current issues relating to psychosocial job strain and cardiovascular disease research. $\mathcal{F}$ 1:9-26.

31 Berkman LF, Syme SL. Social networks, host resistance and mortality: A nine-year follow-up study of Alameda county residents. Am F Epidemiol 1979;109:186-204.

32 Stronks $\mathrm{K}$, van den Mheen $\mathrm{H}$, van den Bos J, et al. The interrelationship between income, health and employment status. Int $\mathcal{F}$ Epidemiol 1997;26:592-600.
33 Leeflang RLI, Klein-Hesselink DJ, Spruit IP. Health effects of unemployment -II. Men and women. Soc Sci Med 1992;

34 Verbrugge LM, Madans JH. Women's roles and health. American Demographics 1985; 7:36-9.

35 Sorensen G. Verbrugge LM. Women, work and health. Annu Rev Public Health 1987;8:235-51.

36 Szulkin R, Tåhlin M. Vardagens villkor (Everyday's conditions). Stockholm: Brombergs förlag, 1994 